\title{
Pemetaan Kualitas Visual Lanskap Pada Daya Tarik Wisata Di Kebun Raya Eka Karya Bedugul
}

\author{
I Gusti Bagus Agung Dwijaksara ${ }^{1 *}$, I Gusti Agung Ayu Rai Asmiwyati ${ }^{1}$, I Made Sukewijaya² \\ 1. Program Studi Arsitektur Lanskap, Fakultas Pertanian, Universitas Udayana, Indonesia 80232 \\ 2. Program Studi Agroekoteknologi, Fakultas Pertanian, Universitas Udayana, Indonesia 80232
}

*E-mail: adwijaksara@gmail.com

\begin{abstract}
The visual landscape quality mapping of tourist attraction in Eka Karya Bedugul Botanical Garden. Eka Karya Bedugul Botanical Garden is a national and international reference to the ex-situ conservation of tropical mountain plant and botanical aspect service, environmental education, horticulture, landscape and tourisms. In order to provide tourism services, actual activities such as conserving and improving the quality of view are needed. The beauty of landscape view is not only determined by enviromental characteristic and landscape wealth, but it also is determined through the assessment of people from their perception over a landscape. The research aimed to map the visual quality landscape in Eka Karya Bedugul Botanical Garden and determine the best criteria of visual quality on natural landscape. The research methods used were surverys and visual assesments which include data collecting step, beauty assesment with scenic beauty estimation (SBE), and descriptive analysis about the determinant factor of visual quality on natural landscape. The beauty of the visual quality over the natural landscape was shown through the harmonic combination of landscape form elements. The visual quality over the natural landscape used were the unity of resources, well maintained natural landscape, and giving a lively effect resulted through the use of combining landscape form elements and design. There were seven landscape points that fall under the best visual quality landscape category, which were landscape number 18,32,33,34,37,38, and 40. The visual landscape quality points in Eka Karya Bedugul Botanical Garden need a regular and persistence maintainence to extend the longevity and aesthetic quality of the natural landscape.
\end{abstract}

Keywords : Visual Landscape Quality, Scenic Beauty Estimation, Eka Karya Bedugul Botanical Garden.

\section{Pendahuluan}

Manusia menemukan fungsi dari lanskap alami sebagai kawasan rekreasi dan bersantai, serta dapat digunakan untuk kegiatan wisata (de Groot et al., 2010). Wisatawan biasanya sangat menghargai lingkungan pegunungan yang masih terjaga dengan baik, sehingga permintaan untuk kegiatan wisata di luar ruangan terus mengalami peningkatan (Raitz \& Dakhil, 1988). Faktor-faktor yang mempengaruhi minat wisatawan terhadap lingkungan pegunungan yaitu keindahan pemandangan, udara segar, topografi yang beragam, dan hutan (Beza, 2010; Scarpa et al., 2000). Pemandangan alami dengan kualitas yang terjaga menjadi nilai jual tinggi dalam destinasi pariwisata di Bali. Salah satu tempat wisata yang berada di lingkungan pegunungan di Bali yang sering dikunjungi para wisatawan adalah Kebun Raya Eka Karya Bedugul (KREKB) yang berlokasi di Desa Candikuning, Kecamatan Baturiti, Kabupaten Tabanan.

KREKB masih memiliki kekurangan dalam memberikan informasi mengenai potensi yang ada, khususnya belum ada pemetaan titik-titik lokasi yang memiliki kualitas visual lanskap yang baik. Pemetaan titik-titik lokasi dengan menilai kualitas visual lanskap yang baik dapat menjadi praktik untuk mempertahankan atau meningkatkan kualitas estetika suatu wilayah (Simonds dan Starke, 2006). Peta kualitas visual lanskap perlu segera disediakan untuk dapat membantu pemangku kepentingan dalam melakukan pemeliharaan atau pengembangan kualitas visual lanskap sehingga daya tarik wisata di KREKB menjadi lebih baik. Salah satu cara untuk memenuhi aspek tersebut yaitu dengan penilaian kualitas keindahan visual lanskap melalui scenic beauty estimation (SBE) sebagai metode pendugaan kualitas estetika melalui perbandingan. Penilaian kualitas keindahan visual merupakan bantuan yang penting bagi perencana dan pemangku kepentingan dalam melestarikan keindahan visual lanskap (Ribe, 2009; Tasser et al., 2012). Studi ini bertujuan untuk memetakan kualitas visual dan menentukan kriteria kualitas visual lanskap alami yang indah, dalam upaya untuk melestarikan atau meningkatkan kualitas visual lanskap alami di KREKB. 


\section{Metode Penelitian \\ 2.1 Tempat dan Waktu Penelitian}

Lokasi penelitian adalah di Kebun Raya Eka Karya Bedugul yang berlokasi di Desa Candikuning, Kecamatan Baturiti, Kabupaten Tabanan, dengan luas 157,5 ha (Kebun Raya Bali, 2013). Lokasi penelitian ditunjukan oleh Gambar 1. Penelitian ini dilakukan selama 6 (enam) bulan yakni bulan November 2019 hingga Mei 2020.

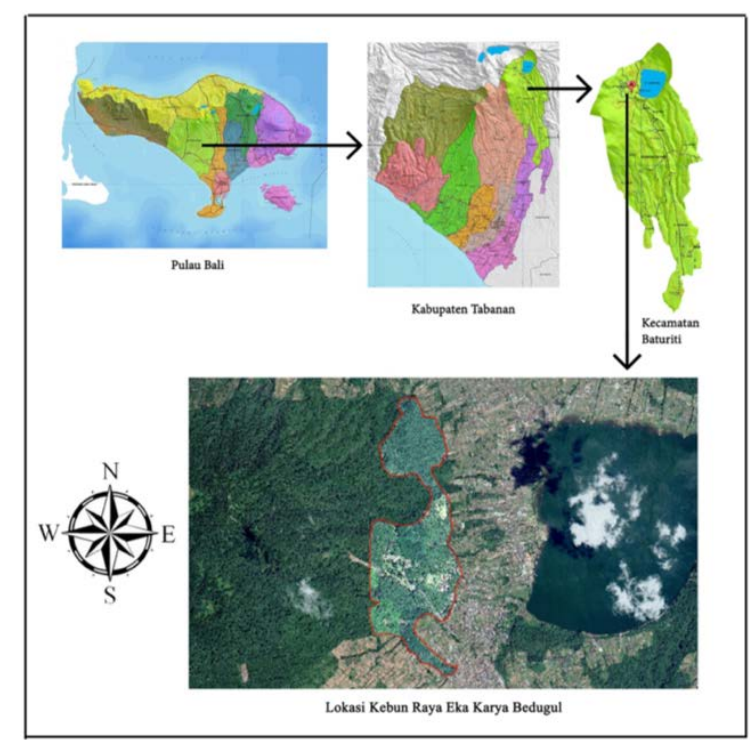

Gambar 1. Lokasi Penelitian

\subsection{Alat dan Bahan}

Adapun alat yang digunakan dalam penelitian ini yaitu, kamera handphone berfungsi sebagai pengambil gambar, peta lokasi penelitian, dan GPS pada smartphone untuk menunjukkan titik koordinat vantage point.

\section{$2.3 \quad$ Metode}

Metode yang digunakan adalah metode survei dan penilaian visual untuk mengetahui persepsi dan preferensi responden terhadap suatu lanskap alami, yang terdiri atas tiga tahap. Tahap pertama merupakan tahap pengumpulan data. Tahap kedua adalah penilaian preferensi yang dilakukan melalui metode scenic beauty estimation (SBE) untuk menduga nilai keindahan lanskap berdasarkan panorama tertentu (Daniel dan Boster, 1976). Tahap ketiga merupakan analisis deskriptif melalui studi pustaka.

\subsubsection{Pengumpulan Data}

Tahap pengumpulan data dilakukan dengan survei awal yang bertujuan untuk memberikan gambaran awal keadaan kawasan sehingga mempermudah penentuan vantage point. Selanjutnya dilakukan pengumpulan data visual yang meliputi tiga kegiatan, yaitu: penentuan vantage point, pemotretan, dan pengelompokan zona jarak. Kriteria penentuan vantage point (VP) dalam penelitian ini terdiri dari: lanskap alami, jarak maksimal dari akses jalan sejauh $400 \mathrm{~m}$, dan area wisatawan berfoto serta bersantai. Indraswara (2007) menyatakan bahwa jarak tempuh berjalan kaki di Indonesia yang masih dianggap nyaman yaitu sejauh kurang lebih $400 \mathrm{~m}$. Tinggi pemotretan yaitu $145 \mathrm{~cm}-155 \mathrm{~cm}$ dengan asumsi setinggi mata manusia dan sejajar dengan pandangan mata normal. Proses pemotretan dilakukan pada pukul 11 pagi -15 sore, dengan kondisi waktu terbaik saat sinar matahari tidak terhalang oleh awan serta tidak adanya kabut. Tahap selanjutnya yaitu pengelompokan zona jarak pada VP yang bertujuan untuk mengetahui penilaian responden terhadap jarak pemandangan yang dilihat dari vantage point. Pengelompokan zona jarak terdiri dari tiga zona yaitu: foreground, middleground, dan background (Bacon, 1979). Foreground yaitu pemandangan dengan bentuk atau dahan daun dari individu vegetasi dapat terlihat dengan jelas. Middleground adalah bagian pemandangan di mana bentuk, atau garis besar, pepohonan dan vegetasi lainnya dapat dibedakan tetapi 
kurang detail. Background adalah pemandangan dengan bentuk tajuk dari satu jenis pohon, tidak dapat dibedakan dengan jenis pohon lainnya (Patsfall et al., 1984).

\subsubsection{Penilaian Preferensi}

Tahap kedua dari penelitian ini adalah penilaian preferensi dengan menggunakan metode SBE yang bertujuan untuk mengetahui jenis lanskap mana saja yang paling menarik menurut responden (Daniel dan Boster, 1976). Persamaan matematik dari rumusan pendugaan nilai keindahan sebagai berikut:

$$
\text { SBEx }=\text { Zyx }- \text { Zyo } \times 100
$$

\section{Keterangan:}

SBEx = Nilai pendugaan keindahan pemandangan suatu lanskap ke-x

$Z y x=$ Nilai rata-rata $z$ lanskap ke- $x$

$z y 0=$ Nilai rata-rata $z$ suatu lanskap tertentu sebagai standar

Proses berikutnya setelah mendapatkan nilai SBE dari masing-masing vantage point yaitu klasifikasi kelas keindahan berdasarkan interval skor. Interval nilai tersebut dibagi menjadi 3 kelas keindahan (baik, sedang, buruk). Interval kelas tersebut ditentukan berdasarkan nilai selisih antara titik maksimum dengan titik minimum data.

\subsubsection{Kuesioner}

Hasil pemotretan lanskap disajikan dalam bentuk gambar slide foto. Slide foto dipresentasikan kemudian dinilai oleh responden dengan pertimbangan skala 1 sampai 10 scenic beauty yaitu skor 1 bernilai tidak suka sampai skor 10 bernilai suka (Daniel dan Boster, 1976). Responden yang melengkapi kuesioner terdiri dari 36 orang mahasiswa Arsitektur Lanskap semester 4 (empat) yang didasarkan pada tingkat pengetahuan tentang lingkungan yang sudah memadai untuk mengisi kuesioner dan telah memiliki pengalaman berkunjung ke KREKB. Tingkat pengetahuan responden tentang lingkungan yang dimaksud yaitu responden diasumsikan sudah memahami dasar-dasar dari faktor yang mempengaruhi keindahan visual lanskap alami. Penilaian responden terhadap pemandangan melalui foto sama baiknya dengan menilai pemandangan secara langsung (Kaplan, 1979). Pelaksanaan presentasi slide foto dilakukan dengan penyebaran kuesioner.

\subsubsection{Analisis Deskriptif}

Analisis deskriptif bertujuan untuk mengungkapkan dan mendeskripsikan elemen-elemen pembentuk karakter kualitas visual lanskap baik. Selain itu, analisis deskriptif melalui studi pustaka bertujuan untuk mendeskripsikan kualitas visual lanskap baik, sedang, dan buruk.

\subsection{Batasan Penelitian}

Lokasi penelitian dilakukan di kawasan Daya Tarik Wisata Kebun Raya Eka Karya Bedugul. Batasan penelitian ini yaitu pengambilan foto untuk penilaian kualitas visual pada lanskap yang bernilai alami saja, serta pembuatan peta lokasi yang memiliki kualitas visual baik.

\section{Hasil dan Pembahasan}

3.1 Gambaran Umum

3.1.1. Letak dan Luas

Kebun Raya Eka Karya Bedugul terletak di Desa Candikuning, Kecamatan Baturiti, Kabupaten Tabanan. Berdasarkan kesepakatan lokasi Kebun Raya ditetapkan seluas 157,5 ha yang meliputi areal hutan reboisasi Candikuning serta berbatasan langsung dengan Cagar Alam Batukau. Lebih dari 2100 jenis tumbuhan yang tersimpan di KREKB merupakan kekayaan yang sangat besar untuk penelitian dan gudang keunikan genetika tumbuhan. KREKB juga terdapat pemandangan dengan nilai estetika yang tinggi, sehingga perlu dijaga kelestariannya.

\subsection{Penentuan Vantage Point}

KREKB terbagi menjadi dua kategori lanskap, yaitu lanskap buatan dan lanskap alami. Tujuan lanskap alami menjadi kriteria penentuan vantage point adalah sebagai batasan penelitian. Lanskap alami yang dimaksud ini adalah bentang alam yang terdapat keragaman yang cukup untuk memungkinkan mata 
mengelompokkan elemen-elemennya, dan kaya akan rangsangan emosional. Kriteria kedua yaitu penentuan vantage point dengan jarak maksimal sejauh $400 \mathrm{~m}$ dari akses jalan. Hal ini bertujuan untuk menjaga kenyamanan wisatawan dalam berjalan, sehingga wisatawan tidak terlalu kelelahan untuk menuju lokasi vantage point. Area KREKB yang menjadi tempat bagi wisatawan untuk bersantai dan berfoto menjadi kriteria terakhir yang dianggap sebagai persepsi pengunjung KREKB dalam melihat suatu visual lanskap alami yang indah. Proses selanjutnya setelah mendapatkan keseluruhan 40 titik vantage point yaitu melakukan pengelompokan ke dalam zona jarak. Hasil pengelompokan vantage point ke dalam zona jarak ditemukan 3 (tiga) vantage point yang mengandung kategori jarak (foreground, middleground, dan background), yaitu vantage point nomor 37, 38, dan 40. Vantage point yang mengandung kategori jarak (foreground dan middleground) berjumlah 22 (duapuluh dua), yaitu vantage point nomor 1, 4, 6, 7, 8, 12, 14, 15, 16, 17, 18, 19, $21,22,23,30,32,33,34,35,36$, dan 39. Vantage Point yang hanya mengandung satu kategori jarak (foreground) berjumlah 11 (sebelas), yaitu vantage point nomor 2, 3, 5, 10, 11, 24, 25, 27, 28, 29, dan 31, dan terdapat 4 (empat) vantage point yang mengandung zona jarak (foreground dan background), yaitu vantage point nomor 9, 13, 20, dan 26.

\subsection{Penilaian Scenic Beauty Estimation}

Keseluruhan 40 vantage point (VP) selanjutnya dilakukan penilaian kualitas visual lanskap alami oleh responden melalui kuesioner. Rata-rata dari hasil penilaian responden terhadap keseluruhan vantage point, kemudian dimasukkan dalam rumus scenic beauty estimation (SBE). Nilai SBE tinggi menunjukkan bahwa kualitas visual lanskap alami tersebut paling banyak dipilih sebagai visual lanskap alami yang baik, sedangkan nilai SBE rendah menunjukkan kualitas yang buruk. Berdasarkan komentar responden pada kuesioner mengenai kualitas visual lanskap alami yang baik, setiap responden memiliki sudut pandang sendiri dalam memberikan nilai. Lanskap alami yang dinilai baik menurut responden cenderung mengarah pada kombinasi antar elemen pembentuk lanskap agar menimbulkan kesan yang harmonis dan nyaman bagi pengunjung.

\subsection{Klasifikasi Kelas Keindahan Kualitas Visual Lanskap}

Hasil akhir penilaian vantage point selanjutnya dilakukan klasifikasi kelas keindahan berdasarkan interval skor. Interval nilai tersebut dibagi menjadi 3 (tiga) kelas keindahan (baik, sedang, dan buruk). Nilai dari foto dengan kualitas visual lanskap yang tinggi berada pada nilai SBE (43 - 84), kualitas visual lanskap sedang nilai SBE (-32 - 43), dan kualitas visual lanskap rendah nilai SBE (-51 - (-32). Nilai klasifikasi kelas keindahan berdasarkan interval skor yang diperoleh melalui nilai selisih antara titik maksimum dengan titik minimum data. Klasifikasi kelas keindahan visual lanskap berfungsi untuk mengetahui kriteria kualitas visual lanskap alami yang baik berdasarkan penilaian kualitas visual.

Penilaian kualitas visual lanskap mengacu pada penelitian Iverson et al (1993) yang menyatakan parameter yang digunakan untuk menilai kualitas visual lanskap yaitu: kesatuan sumber daya visual lanskap dalam membentuk suatu unit visual yang harmonis, keutuhan kondisi lanskap alami, serta kesan hidup dari penggabungan elemen-elemen desain dan pembentuk suatu lanskap. Kriteria kualitas visual lanskap yang baik menjadi acuan bagi kualitas visual lanskap sedang dan buruk, agar dapat meningkatkan kualitasnya sehingga dapat mendekati kriteria kualitas visual lanskap baik.

\subsubsection{Kualitas Visual Lanskap Baik}

Kriteria kualitas visual lanskap yang baik yaitu memiliki kesatuan sumber daya visual yang harmonis, kondisi lanskap alami masih terjaga dengan baik, dan memberikan kesan hidup dari penggabungan elemenelemen desain dan pembentuk lanskap. Kesatuan sumber daya visual yang ditemukan pada titik-titik lanskap yang baik, berupa kesan harmonis yang ditimbulkan dari kesatuan antara man made dan softscape. Pengaruh background juga menjadi salah satu unsur penting yang mendukung kesatuan sumber daya visual, seperti jajaran bukit dan Danau Beratan yang terlihat dari kawasan Kebun Raya Eka Karya Bedugul. Titik-titik lanskap yang masuk dalam kategori kualitas visual lanskap baik, keutuhan lanskap alaminya masih terjaga. Perawatan vegetasi yang baik dapat memberikan nuansa yang segar dan alami. Kriteria kesan hidup dari penggabungan elemen-elemen pembentuk lanskap menjadi parameter terakhir yang mempengaruhi penilaian responden. Berdasarkan hasil kuesioner, elemen-elemen tersebut terdiri dari vegetasi, warna, cahaya. Karakter visual vegetasi memiliki nilai estetika yang memberikan pengaruh terhadap kualitas visual lanskap.

Hal menarik yang ditemukan dari keseluruhan titik lanskap dengan kualitas visual baik yaitu, satu titik lanskap masuk dalam lebih dari satu kategori zona jarak. Berdasarkan pernyataan tersebut, menandakan 
bahwa responden cenderung menyukai pemandangan dengan jarak view yang dilihat cukup jauh, sehingga dapat mencakup objek yang lebih beragam. Selain itu, titik lanskap yang masuk dalam ketiga kategori zona jarak seluruhnya memperoleh nilai yang tinggi dari responden. Titik lanskap yang memperoleh nilai tertinggi dari hasil penilaian responden yaitu foto 33 dengan perpaduan zona jarak foreground dan middleground. Arah pandang menjadi faktor penentu tingginya penilaian responden, karena view yang terlihat merupakan interpretasi dari karakter tapak dan KREKB.

Hasil dari penilaian responden, terdapat 7 (tujuh) buah titik lanskap yang masuk dalam kategori kualitas visual lanskap baik, yaitu foto nomor $18,32,33,34,37,38$, dan 40 . Peta titik lanskap dengan kualitas visual lanskap yang baik disajikan pada Gambar 2. Pemetaan berfungsi untuk mengetahui titik-titik dengan kualitas visual lanskap yang baik di KREKB, sehingga mempermudah pencarian lokasi. View yang terlihat dari vantage point sudah sesuai dengan titik koordinat di lapangan sehingga dapat menjadi database bagi pemangku kepentingan di KREKB dalam melakukan pemeliharaan atau pengembangan terkait titik kualitas visual lanskap baik. Selain itu, tujuan dari menentukan kriteria kualitas visual lanskap yang baik yaitu agar menjadi acuan bagi pemangku kepentingan di KREKB dalam melakukan pemeliharaan terhadap titik kualitas visual lanskap sedang dan buruk. Hasil pemeliharaan tersebut diharapkan dapat memberikan daya tarik bagi wisatawan.

\subsubsection{Kualitas Visual Lanskap Sedang}

Titik lanskap yang termasuk dalam kategori kualitas visual lanskap sedang berjumlah 27 titik, yaitu foto $3,4,5,6,7,8,9,10,11,12,13,14,15,16,17,19,20,22,23,26,27,29,30,31,35,36$, dan 39. Kualitas visual lanskap sedang cenderung mengarah pada kondisi tapak yang terdapat vegetasi kurang terawat, namun masih memiliki nilai estetika. Nilai estetika yang terdapat pada tapak dengan kualitas visual lanskap sedang yaitu adanya pepohonan rimbun serta karakter tajuk pohon yang memberikan kesan alami dan indah. Hasil penilaian responden menunjukan bahwa keseluruhan titik lanskap yang masuk dalam kategori kualitas visual lanskap sedang, pada pengelompokan zona jarak tidak ada yang mengandung ketiga zona jarak dalam satu titik lanskap. Pengelompokkan zona jarak mempengaruhi penilaian responden berdasarkan keragaman objek yang terlihat. Kekurangan dari titik lanskap dengan kualitas visual lanskap sedang terletak pada objek yang dilihat masih kurang beragam, sehingga responden cenderung memberikan penilaian yang sedang.

\subsubsection{Kualitas Visual Lanskap Buruk}

Hasil penilaian responden terdapat 6 (enam) titik lanskap yang masuk dalam kategori kualitas visual lanskap buruk, yaitu foto 1, 2, 21, 24, 25, dan 28. Faktor yang mempengaruhi rendahnya penilaian responden adalah penataan elemen hardscape yang kurang harmonis dengan elemen softscape, kondisi tapak cenderung gelap yang disebabkan oleh bayangan dari vegetasi di zona foreground, dan kondisi rumput yang tidak subur. Tinggi dan jenis vegetasi yang kurang beragam juga mempengaruhi penilaian yang rendah dari karena memberikan kesan monoton. Hal menarik yang ditemukan berdasarkan penilaian responden yaitu dari 6 (enam) titik lanskap yang masuk dalam kategori kualitas visual buruk, cenderung lebih banyak hanya mengandung satu jenis kategori jarak. Hasil penilaian tersebut membuktikan bahwa responden kurang menyukai view yang hanya mencakup satu kategori zona jarak. Kategori jarak (foreground, middleground, dan background) diduga menentukan penilaian terhadap baik-buruknya pemandangan oleh responden, selain dari variasi elemen pembentuk lanskap. Pemangku kepentingan di KREKB perlu meningkatkan titik lanskap dengan kualitas visual lanskap buruk agar dapat mendekati kriteria visual lanskap baik. Hal tersebut bertujuan untuk meningkatkan kualitas visual lanskap alami di kawasan KREKB sehingga mampu memberikan kesan yang baik bagi wisatawan. Rangkuman kriteria dari masing-masing kelas keindahan kualitas visual lanskap dapat dilihat pada Tabel 2 . 


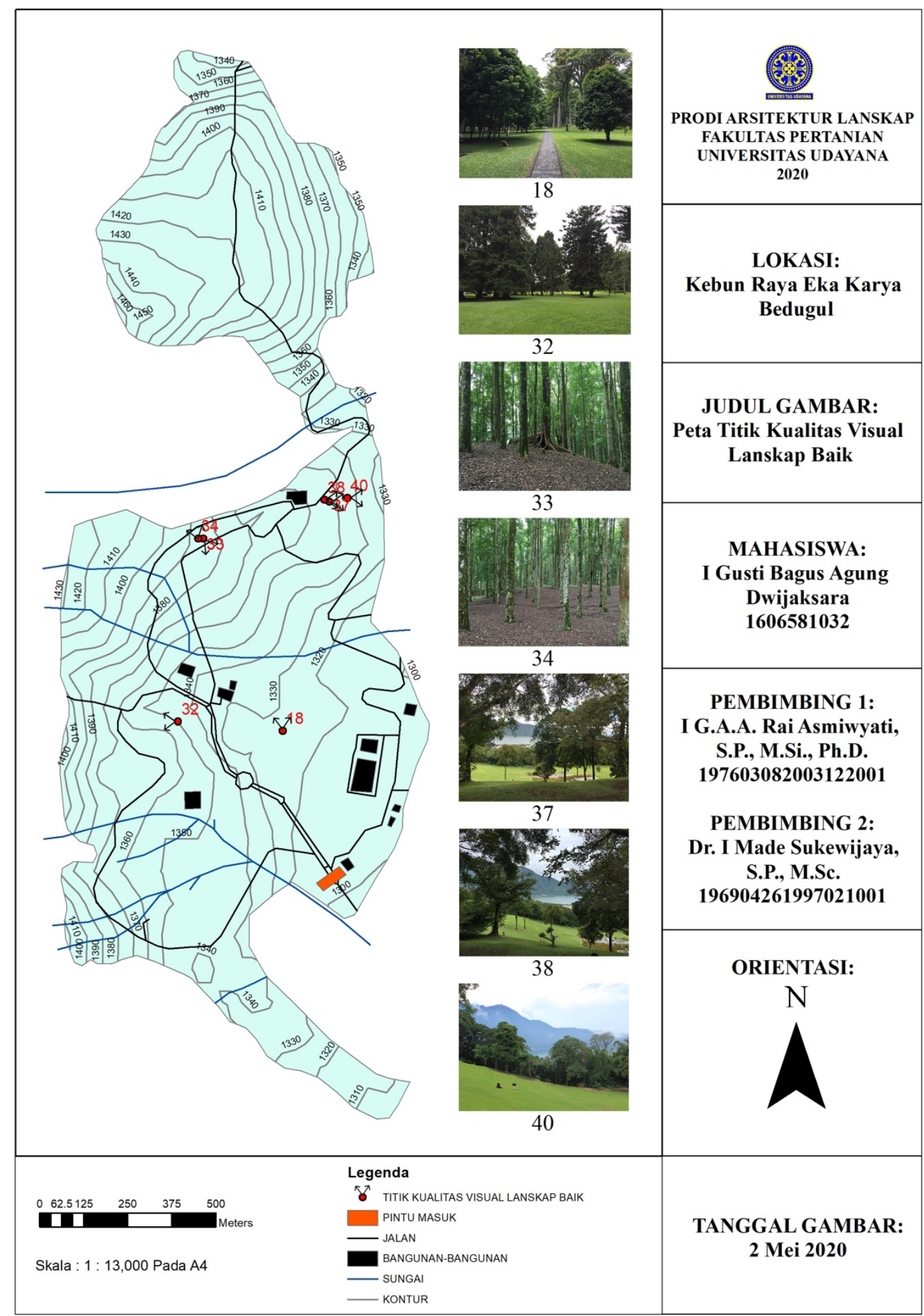

Gambar 2. Peta Titik Lanskap Kualitas Visual Baik 
Tabel 2. Tabel Kriteria Kelas Keindahan Lanskap

\begin{tabular}{|c|c|c|c|}
\hline No. & Kelas Keindahan & Vantage Point & Kriteria \\
\hline 1. & Baik & $\begin{array}{l}\text { Foto nomor } 18,32,33 \\
34,37,38 \text {, dan } 40\end{array}$ & $\begin{array}{l}\text { Kesatuan sumber daya visual berupa kesan } \\
\text { harmonis yang ditimbulkan dari kesatuan antara } \\
\text { man made dan softscape serta pengaruh } \\
\text { background seperti jajaran bukit dan Danau } \\
\text { Beratan memberikan kesan yang indah, } \\
\text { keutuhan lanskap alaminya masih terjaga yang } \\
\text { ditandai dengan kesuburan dari vegetasi, kesan } \\
\text { hidup dari penggabungan elemen-elemen } \\
\text { desain dan pembentuk lanskap berupa } \\
\text { vegetasi, warna, dan cahaya (vegetasi dilihat } \\
\text { dari karakter dan komposisi, warna terdiri dari } \\
\text { hijau, biru, putih, dan merah yang dapat } \\
\text { memberikan kesan sejuk, segar, dan } \\
\text { pencahayaan yang baik, serta cahaya yang } \\
\text { baik yaitu tidak silau dan gelap) }\end{array}$ \\
\hline 2. & Sedang & $\begin{array}{l}\text { Foto nomor } 3,4,5,6,7 \\
8,9,10,11,12,13,14 \\
15,16,17,19,20,22 \\
23,26,27,29,30,31 \\
35,36 \text {, dan } 39\end{array}$ & $\begin{array}{l}\text { Kondisi tapak dengan vegetasi kurang } \\
\text { terpelihara dengan baik namun masih memiliki } \\
\text { nilai estetika, keadaan rumput yang tumbuh } \\
\text { kurang subur namun adanya pepohonan } \\
\text { rimbun serta karakter tajuk pohon yang } \\
\text { memberikan kesan alami dan indah, objek yang } \\
\text { terlihat masih kurang beragam }\end{array}$ \\
\hline 3. & Buruk & $\begin{array}{l}\text { Foto nomor } 1,2,21,24 \text {, } \\
25 \text {, dan } 28\end{array}$ & $\begin{array}{l}\text { Penataan elemen hardscape yang kurang } \\
\text { harmonis dengan elemen softscape yang ada } \\
\text { pada tapak, kondisi tapak cenderung gelap, } \\
\text { tinggi dan jenis vegetasi yang kurang beragam, } \\
\text { kondisi rumput kurang subur }\end{array}$ \\
\hline
\end{tabular}

\subsection{Karakteristik Titik Kualitas Visual Lanskap Baik}

Menurut Bacon (1979) karakteristik lanskap adalah suatu lanskap alami yang secara visual menunjukkan kesan harmonis dari pola vegetasi dan elemen-elemen pembentuk lanskap. Karakter tersebut diperoleh berdasarkan analisis terhadap elemen-elemen pembentuk lanskap dengan kualitas visual baik. Elemen pembentuk karakter lanskap pada titik-titik lanskap kualitas visual baik berdasarkan hasil penilaian responden terdiri dari: vegetasi, warna, air, dan cahaya. Hasil yang diperoleh setelah melakukan analisis yaitu terdapat tiga karakter lanskap yang berbeda dari 7 (tujuh) titik lanskap dengan kualitas visual baik. Pembagian karakter lanskap tersebut yaitu: karakter lanskap I (foto 37, foto 38, dan foto 40), karakter lanskap II (foto 33 dan foto 34), dan karakter lanskap III (foto 32 dan Foto 18).

\subsection{Rekomendasi Penataan Kawasan}

Tindak lanjut dari hasil penilaian kualitas visual lanskap di KREKB yaitu melakukan modifikasi terhadap titik-titik lanskap yang tergolong dalam kategori kualitas visual lanskap sedang dan buruk. Titik lanskap dengan kualitas visul baik juga perlu adanya modifikasi, karena masih memiliki kekurangan seperti adanya elemen vegetasi yang dapat menghalangi view. Hal tersebut bertujuan untuk mengintensifkan kualitas visual lanskap di KREKB sehingga diharapkan mampu meningkatkan nilai estetika serta memberikan kesan yang baik bagi wisatawan. Modifikasi dalam hal ini terdiri dari dua langkah yang dapat dilakukan yaitu, menghilangkan elemen lanskap yang tidak sesuai dan intensifikasi (Simonds, 1983).

KREKB menyediakan layanan publik untuk kegiatan fotografi/videografi dalam mengabadikan kunjungan bagi wisatawan. Terdapat aturan dari pihak KREKB untuk menjaga kenyamanan wisatawan saat melakukan kegiatan fotografi/videografi (Kebun Raya Bali, 2013). Aturan tersebut yaitu:

1. Tidak memasuki area bunga dan tanaman koleksi, tetap berada di jalan setapak atau lapangan rumput

2. Tidak boleh membawa minuman keras ke dalam kebun

3. Dilarang mengambil atau memindahkan tanaman, label tanaman atau tempat sampah

4. Tidak menghalangi jalan masuk, jalan setapak atau area yang digunakan pengunjung lain.

Untuk mendukung layanan publik KREKB khususnya kegiatan fotografi dan tidak melanggar aturan yang telah ditetapkan, perlu adanya jalur wisata untuk menikmati pemandangan dengan kualitas visual lanskap yang baik. Pengadaan jalur wisata juga merupakan salah satu praktik modifikasi yaitu langkah intensifikasi (Simonds, 1983). Peta dengan jalur wisata tersebut dapat dilihat pada Gambar 3. Penyediaan interpretive sign pada tiitk 
lanskap kualitas visual baik juga menjadi rekomendasi bagi pemangku kepentingan di KREKB, untuk memberikan informasi bagi wisatawan agar mengetahui posisi pengambilan gambar yang sesuai dengan hasil penelitian.

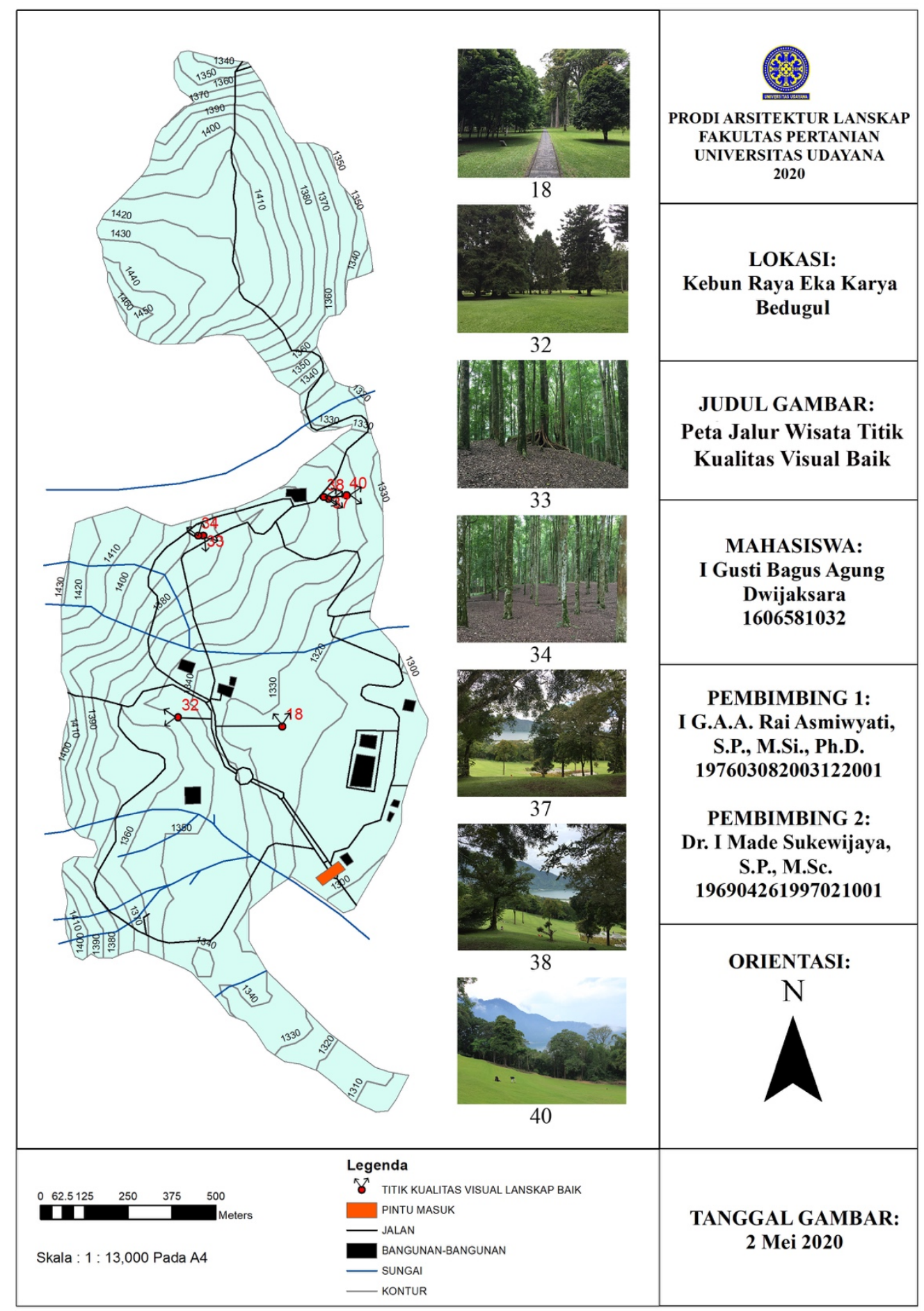

Gambar 3. Peta Jalur Wisata Titik Kualitas Visual Baik 
4. Penutup

4.1 Simpulan

Berdasarkan hasil penelitian yang dilakukan di KREKB dapat disimpulkan sebagai berikut:

1. Studi penilaian keindahan pemandangan (metode scenic beauty estimation) di Kebun Raya Eka Karya Bedugul (KREKB) melalui foto oleh 36 responden yang memiliki latar belakang ilmu arsitektur lanskap menghasilkan tujuh buah titik lanskap (foto nomor 18, 32, 33, 34, 37, 38, dan 40) yang termasuk dalam kategori kualitas visual lanskap baik. Hasil ini menjadi dasar penyusunan produk akhir berupa peta visual lanskap yang baik di KREKB. Kriteria yang digunakan untuk menentukan titik lanskap vantage point (VP) yaitu titik dengan dominasi lanskap alami, maksimal $400 \mathrm{~m}$ dari jalan, dan tempat berfoto serta bersantai oleh wisatawan sehingga dihasilkan $40 \mathrm{VP}$. Untuk mengetahui faktor/kriteria yang mendasari suatu titik lanskap dinilai sebagai lanskap dengan visual yang baik dilakukan analisis terhadap jawaban deskriptif responden, mengelompokkan VP ke dalam zona jarak (foreground, middleground, dan background), dan mengkaitkan kondisi VP dengan teori keindahan lanskap.

2. Kriteria kualitas visual lanskap alami yang baik adalah kondisi lanskap yang secara visual terbentuk oleh kombinasi yang harmonis, antara elemen-elemen pembentuk lanskap sehingga menimbulkan kesan yang indah bagi wisatawan. Kriteria kualitas visual lanskap yang baik terdiri dari: keutuhan kondisi lanskap alami (kondisi vegetasi yang terpelihara dengan baik), elemen-elemen pembentuk lanskap dan desain (vegetasi, cahaya, warna, air) serta sumber daya visual lanskap (softscape, hardscape, dan background). Hal menarik yang ditemukan dari keseluruhan titik lanskap dengan kualitas visual baik, yaitu keseluruhan titik lanskap mengandung lebih dari satu kategori zona jarak (kombinasi foreground, middleground, dan atau background). Adanya variasi jarak jangkauan visual dari VP diduga turut mempengaruhi penilaian kualitas visual lanskap alami. Adanya kombinasi jarak jangkauan visual memunculkan keindahan visual yang lebih dinamis atau tidak monoton.

\subsection{Saran}

Berdasarkan hasil penelitian yang dilakukan di KREKB dapat diajukan saran sebagai berikut:

1. Titik Titik-titik kualitas visual lanskap baik yang ada di KREKB perlu adanya pemeliharaan yang berkelanjutan, untuk menjaga kualitas estetika dari visual lanskap alami demi menjaga kelestariannya.

2. Pemangku kepentingan di KREKB juga dapat menggunakan peta dalam melakukan pemeliharaan atau pengembangan kualitas visual lanskap alami, selain sebagai informasi bagi pengunjung untuk dapat mencari lokasi pemandangan yang indah dengan waktu yang lebih efisien.

3. Penelitian visual yang dikaitkan pemeliharaan berkelanjutan dapat menjadi topik bagi penelitian di masa mendatang.

\section{Daftar Pustaka}

Bacon, W. R. (1979). The visual management system of the Forest Service, USDA. Forest Service, U.S. Department of Agriculture: pp. 660-665.

Beza, B.B. (2010). The aesthetic value of a mountain landscape: A study of the Mt. Everest Trek. Landscape and Urban Planning, 97, 306-317.

Daniel, T. C. dan R. S. Boster. (1976). Measuring Landscape Esthetic: The Scenic Beauty Estimation Method. US For., Serv., Pap., RM-167.

de Groot, R., Alkemade, R., Braat, L., Hein, L. and Willemen, L., (2010). Challenges in integrating the concept of ecosystem services and values in landscape planning, management and decision making. Ecological Complexity, 7(3), pp.260-272.

Indraswara, M. S. (2007). Kajian Kenyamanan Jalur Pedestrian Pada Jalan Imam Barjo, Semarang. Jurnal IImiah Perancangan Kota dan Permukiman, 6(2):59-69.

Iverson, W. D., S. R. Sheppard dan R. A. Strain. (1993). Managing regional scenic quality in the Lake Tahoe basin. Landscape Journal. Spring 1993 vol. 12 no. 1 23-39.

Kaplan, S. (1979). Perception and Landscape Conceptions and Misconceptions. Proceeding of Our National Landscape Conference. USDA Forest Service. California. 241 hal.

Kebun Raya Bali. (2013). Sejarah Kebun Raya Eka Karya Bedugul. Tersedia pada: https://www.kebunrayabali.com/sitemap.html (diakses pada: 12 Oktober 2019).

Patsfall, M., Feimer, N., Buhyoff, G. and Wellman, J. (1984). The prediction of scenic beauty from landscape content and composition. Journal of Environmental Psychology, 4(1), pp.7-26. 
Raitz, K. and Dakhil, M. (1988). Recreational choices and environmental preference. Annals of Tourism Research, 15, 357-370.

Ribe, R. G. (2009). In-stand scenic beauty of variable retention harvests and mature forest in the U.S. Pacific Northwest: The effects of basal area, density, retention pattern and down wood. Journal of Environmental Management, 91, 245-260.

Scarpa, R., Chilton, S.M., Hutchinson, W. G., and Buongiorno, J. (2000). Valuing the recreational benefits from the creation of nature reserves in Irish forest. Ecological Economics, 33, 237-250.

Shodiq, M. A., T. Budiarti, N. Nasrullah. (2018). Kajian Potensi Koleksi Pohon Lokal Kebun Raya Cibodas Untuk Fungsi Estetika Dalam Lanskap. Jurnal Lanskap Indonesia, 10(1):1-3. doi: 10.31226/osf.io/7abuq.

Tasser, E., Schermer, M., Siegl, G., and Tappeiner, U. (2012). Wir LandschaftMacher - Vom Sein und Werden der Kulturlandschaft in Nord-, Sud- und Osttirol (We landscape maker - development of the cultural landscape in north, South and East Tyrol). Bozen: Athesia.

Simonds, J. O. (1983). Landscape Architecthure. Mc Graw-Hill Book Company, Inc. New York. 244p. 